\title{
Predicting acute coronary syndrome in males and females with chest pain who call an emergency medical communication centre
}

Paul-Georges Reuter ${ }^{1,2,3^{*}}$ (D), Catherine Pradeau4 ${ }^{4}$ Samantha Huo Yung Kai ${ }^{2,5}$, Thibault Lhermusier ${ }^{6}$, Arnaud Bourdé Eric Tentillier ${ }^{4}$, Xavier Combes ${ }^{7}$, Vanina Bongard ${ }^{2,5}$, Jean-Louis Ducassé ${ }^{1}$ and Sandrine Charpentier ${ }^{1,2}$

\begin{abstract}
Background: Chest pain is a frequent reason for calls in emergency medical communication centre (EMCC). Detecting a coronary origin by phone is a challenge. This is especially so as the presentations differ according to gender. We aimed to establish and validate a sex-based model to predict a coronary origin of chest pain in patients calling an EMCC.

Methods: This prospective cohort study enrolled patients at 18 years of age or older who called the EMCC because of non-traumatic chest pain. The main outcome was the diagnosis of acute coronary syndrome (ACS) determined by expert evaluation of patient files.

Results: During 18 months, 3727 patients were enrolled: 2097 (56\%) men and 1630 (44\%) women. ACS was diagnosed in 508 (24\%) men and 139 (9\%) women. For men, independent factors associated with an ACS diagnosis were age, tobacco use, severe and permanent pain; retrosternal, breathing non-related and radiating pain; and additional symptoms. The area under the receiver operating characteristic curve (AUC) was 0.76 (95\% confidence interval [CI] $0.73-0.79)$ for predicting ACS. The accuracy of the male model to predict ACS was validated in a validation dataset (Hosmer-Lemeshow test: $p=0.554)$; the AUC was 0.77 (95\%Cl 0.73-0.80). For women, independent factors associated with an ACS diagnosis were age $\geq 60$ years, personal history of coronary artery disease, and breathing non-related and radiating pain. The AUC was $0.79(95 \% \mathrm{Cl} 0.75-0.83)$. The accuracy of the female model to predict ACS was not validated in the validation dataset (Hosmer-Lemeshow test: $p=0.035$ ); the AUC was 0.67 (95\% $0.60-0.74$ ).
\end{abstract}

Conclusions: Predictors of an ACS diagnosis in patients calling an EMCC for chest pain differ between men and women. We developed an accurate predictive model for men, but for women, the accuracy was poor.

Trial registration: This study is registered with ClinicalTrials.gov (NCT02042209).

Keywords: Chest pain, Acute coronary syndrome, Emergency medical communication Centre, Accuracy, Sex disparity

\section{Background}

Acute coronary syndrome (ACS) is a frequent pathology worldwide. Management consists in coronary reperfusion, by percutaneous intervention or fibrinolysis. The worst evolution consists in ventricular fibrillation and cardiac arrest. Survival depends on the total ischemic

\footnotetext{
* Correspondence: paul-georges.reuter@aphp.fr

${ }^{1}$ Emergency Department, Toulouse University Hospital, 31000 Toulouse, France

${ }^{2}$ UMR 1027, Paul Sabatier University Toulouse III, Inserm, Toulouse, France Full list of author information is available at the end of the article
}

time: delay between chest pain onset and reperfusion [1]. The main symptom is chest pain or discomfort [2]. The first link for out-of-hospital chain of survival is patient education to call the emergency medical communication centre (EMCC) in case of chest pain. The second is the ability of the dispatcher, medical or not, to identify patients with ACS and to send an ambulance (with an emergency physician or not, depending on the country).

In a Copenhagen EMCC, chest pain was the second identified reason after minor trauma for calls, with $11 \%$ of the requests [3]. The sex ratio was 1:1 and over half of the

(c) The Author(s). 2019 Open Access This article is distributed under the terms of the Creative Commons Attribution 4.0 International License (http://creativecommons.org/licenses/by/4.0/), which permits unrestricted use, distribution, and reproduction in any medium, provided you give appropriate credit to the original author(s) and the source, provide a link to the Creative Commons license, and indicate if changes were made. The Creative Commons Public Domain Dedication waiver (http://creativecommons.org/publicdomain/zero/1.0/) applies to the data made available in this article, unless otherwise stated. 
patients were over 65 years of age [4]. When a contact occurred with an EMCC, the prevalence at 30 days of ACS ranged from 12 to $16 \%[5,6]$. For patients with ACS, the use of the EMCC was in the range of 23 to $43 \%$ [7, 8]. Patients with ST elevation myocardial infarction (STEMI) were given the highest priority in $82 \%$ of cases [9].

ACS diagnosis depends on electrocardiography (ECG) findings and biomarkers. At an EMCC, these data are not available. Only patient history and characteristics of chest pain can be investigated. A persistent pain or a typical location with radiation without associated symptoms influences the dispatcher to send a Mobile Intensive Care Unit (MICU) in France [10]. In Sweden, the intensity, the localisation of the pain and a history of ischemic heart disease were associated with the final diagnosis of ACS [11]. The accuracy of a computer-based decision support was compared with dispatchers' decisions to predict ACS [5]. Sensitivity was greater with the computer- than dispatcher-based decision $(90 \%$ vs. $83 \%)$, and that under triage (false negative) was 10 and $17 \%$, respectively. The factors correlated to under triage were the time of the call (lunch time) and the level of medical knowledge of the dispatcher (assistant nurse versus dispatcher with no medical training) [12]. These findings confirm the need for a decision support tool to help dispatchers identify patients at risk of ACS.

Atypical clinical presentations are difficult to diagnose [13]. In older and diabetic patients, chest discomfort can be absent $[14,15]$. Males and females also differ in clinical presentation of ACS [2]. Women, particularly those $<55$ years old, most often describe atypical chest pain, such as discomfort, pinching, or burning, [16-20]. These differences in initial presentation lead to an increase in mortality among women (10\% versus $5 \%$ ) [21]. Total ischemic time is longer in women than men $[8,9,22]$. One explanation is a lower prioritization for women when calling call centres $(79 \%$ for women and $89 \%$ for men) [9]. These results suggest that attention should be paid to recognize these patients as soon as possible. In creating a "by-phone" predictive score of ACS, items should differ according to sex.

We aimed to establish and validate a model to predict ACS for men and women calling an EMCC from information that can be recorded by phone.

\section{Methods}

\section{Study design and setting}

The DOREMI 2 prospective cohort study was conducted in three French university hospitals. This study is a follow-up to DOREMI 1, which was a pilot and feasibility study. The three participating EMCCs were located in Toulouse, Bordeaux and Saint-Denis de la Réunion. In 2017, the EMCCs served 1.318, 1.506 and 0.843 million inhabitants, respectively. After an evaluation by a dispatcher assistant, a physician manages every call for medical reasons. Depending on the dispatcher prioritization, calls are handled by a general practitioner or an emergency physician. In France, calls from patients with chest pain or discomfort are generally transferred to the emergency physician dispatcher. In response to a call, a medical dispatcher can give medical advice, recommend going into a medical care structure or send an ambulance, fire brigade, physician or MICU (ambulance with an emergency physician on board).

\section{Selection of participants}

From May 2010 to November 2011, we consecutively included adults at 18 years of age or older who called the EMCC for non-traumatic chest pain. The "non-traumatic" characteristic was verified directly by asking the patient. The exclusion criterion was any difficulty in communicating: uncommunicative patient, language barrier, or inability to speak with the patient.

\section{Measurements}

At the first call to the EMCC, the emergency physician recorded patient characteristics, cardiovascular risk factors, medical history and clinical presentation on a standardized form (Additional file 1). Follow-up data were collected 30 days after the call (D30) by telephone interview. A research assistant contacted the patient's general practitioner and/or the patient directly. The patient was contacted in case of non-response from the general practitioner or in case of incomplete information.

At the D30 follow-up, the research assistant retrieved reports from the emergency department, hospitalization and additional examinations. They collected data on major adverse cardiovascular events (rehospitalisation, myocardial infarction, urgent revascularization or death), admission or a consultation in a cardiology unit, non-invasive imaging (transthoracic echocardiography, stress imaging with exercise or drug, cardiac MRI), coronary angiography and the final diagnosis during hospitalization. The final diagnosis of ACS was based on these data.

\section{Outcome}

The outcome was a diagnosis of ACS by experts according to current guidelines [23].

STEMI was defined by the onset of a persistent STelevation on ECG, considered suggestive in the following cases: 1) at least two continuous leads with ST-segment elevation $>0.2 \mathrm{mV}$ in leads $\mathrm{V} 1-\mathrm{V} 3$ or $>0.1 \mathrm{mV}$ in leads V4-V9, V3R and V4R or 2) left bundle branch block with the presence of concordant ST-segment elevation.

Non-STEMI was diagnosed with compatible clinical presentation and ECG abnormalities in two continuous leads such as ST-segment depression or T-wave changes and elevated cardiac troponin level higher than the 99th percentile.

Unstable angina was considered when the patient had a compatible clinical presentation and ECG abnormalities 
without elevated cardiac troponin level and at least one of the following abnormalities: 1) dynamic changes of the ST-segment within 30 days or during the stress test; 2) a positive test result from stress echocardiography, cardiac MRI, coronary CT angiography; 3 ) coronary angiography with $>70 \%$ occlusion, 4) death within 30 days and, 5) rehospitalisation within 30 days with a diagnosis of ACS.

All patient files were retrospectively analysed by two experts to determine the final diagnosis of ACS or not. Three pairs of experts were recruited from the three centres. They did not belong to the team that included or cared for the patient. Files were randomly assigned. In case of discordance between the two experts, a third one was consulted. The diagnosis was based on pre-hospital data, reports of emergency departments, hospitalization and/or additional examinations, and follow-up on D30.

\section{Analysis \\ Sample size calculation}

At least 10 events per independent variable are recommended to ensure satisfactory statistical power in multivariate regression models $[24,25]$. Because we planned to include a maximum of 15 independent variables in the final predictive model for each sex, we needed 150 calls with ACS for men and 150 for women. Given that approximately $16 \%$ of calls for non-traumatic chest pain have a definite diagnosis of ACS in the French EMCC, we needed 938 calls for each sex [6]. Given that the percentage of lost to follow-
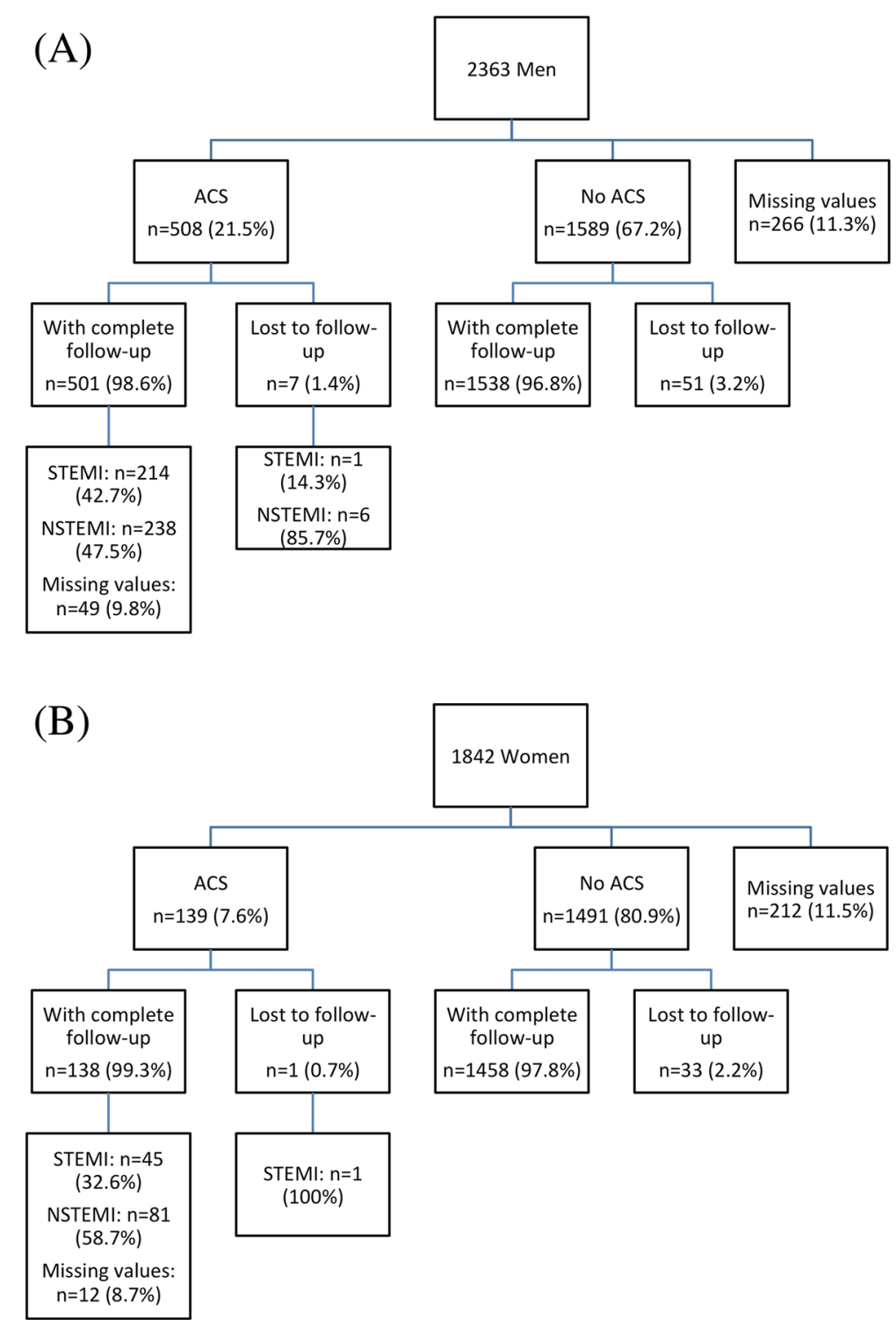

Fig. 1 Flowchart based on final diagnosis for men (a) and women (b). ACS: Acute Coronary Syndrome; NSTEMI: Non ST Elevation Myocardial Infarction; STEMI: ST Elevation Myocardial Infarction 
Table 1 Characteristics and type of pain for male patients in the derivation set with and without a diagnosis of acute coronary syndrome (ACS)

\begin{tabular}{|c|c|c|c|c|}
\hline & Total $(n=1398)$ & $\operatorname{ACS}(n=329)$ & No ACS $(n=1069)$ & $p$ value \\
\hline Age, mean (SD), y, No. (\%) & $59.2(16.1)$ & $59.4(13.2)$ & $50.9(16.4)$ & $<0.001$ \\
\hline$<40$ & $291(20.8)$ & $18(5.5)$ & $273(25.5)$ & $<0.001$ \\
\hline $40-50$ & $317(22.7)$ & $59(17.9)$ & $258(24.1)$ & \\
\hline $50-60$ & $320(22.9)$ & $95(28.9)$ & $225(21.0)$ & \\
\hline$\geq 60$ & $470(33.6)$ & $157(47.7)$ & $313(29.3)$ & \\
\hline \multicolumn{5}{|l|}{ Coexisting conditions, No. (\%) } \\
\hline Hypertension & $405(29.0)$ & $123(37.4)$ & $282(26.4)$ & $<0.001$ \\
\hline Personal coronary artery disease & $387(27.7)$ & $126(38.3)$ & $261(24.4)$ & $<0.001$ \\
\hline Family coronary artery disease & $231(16.5)$ & $51(15.5)$ & $180(16.8)$ & 0.568 \\
\hline Tobacco use & $545(39.0)$ & $133(40.4)$ & $412(38.5)$ & 0.540 \\
\hline Diabetes & $183(13.1)$ & $59(17.9)$ & $124(11.6)$ & 0.003 \\
\hline Dyslipidaemia & $337(24.1)$ & $97(29.5)$ & $240(22.5)$ & 0.009 \\
\hline \multicolumn{5}{|l|}{ Medication therapy, №. (\%) } \\
\hline Aspirin & $296(21.2)$ & $100(30.4)$ & $196(18.3)$ & $<0.001$ \\
\hline Clopidogrel & $209(14.9)$ & $77(23.4)$ & $132(12.3)$ & $<0.001$ \\
\hline Thyroid hormone & $12(0.9)$ & $2(0.6)$ & $10(0.9)$ & 0.743 \\
\hline Statin & $263(18.8)$ & $87(26.4)$ & $176(16.5)$ & $<0.001$ \\
\hline Severity of pain, median (IQR) & $5[3-7]$ & $5[4-7]$ & $5[3-7]$ & $<0.001$ \\
\hline \multicolumn{5}{|l|}{ Type of pain, No. (\%) } \\
\hline Severe pain (NRS $\geq 6$ ) & $592(42.4)$ & $162(49.2)$ & $430(40.3)$ & 0.004 \\
\hline Permanent & $350(25.0)$ & $102(31.0)$ & $248(23.2)$ & 0.004 \\
\hline Pain onset: & & & & 0.066 \\
\hline Crescendo & $307(22.0)$ & $67(20.4)$ & $240(22.5)$ & \\
\hline Abruptly & $590(42.2)$ & $157(47.7)$ & $433(40.5)$ & \\
\hline Unclassified & $501(35.8)$ & $105(31.9)$ & $396(37.0)$ & \\
\hline Circumstance of pain, №. (\%) & & & & 0.012 \\
\hline At rest & $1106(79.1)$ & $244(74.2)$ & $862(80.6)$ & \\
\hline Sport or stress-related & $180(12.9)$ & $58(17.6)$ & $122(11.4)$ & \\
\hline Unclassified & $112(8.0)$ & $27(8.2)$ & $85(8.0)$ & \\
\hline \multicolumn{5}{|l|}{ Pain typography, No. (\%) } \\
\hline Typical chest pain ${ }^{a}$ & $799(57.2)$ & $224(68.1)$ & $575(53.8)$ & $<0.001$ \\
\hline Retrosternal & $671(48.0)$ & $201(61.1)$ & $470(44.0)$ & $<0.001$ \\
\hline Post-myocardial infarction angina & 119/387 (30.8) & $50 / 126(39.7)$ & $69 / 261(24.4)$ & 0.008 \\
\hline Peak type & $260(18.6)$ & $28(8.5)$ & $232(21.7)$ & $<0.001$ \\
\hline Burning & $182(13.0)$ & $51(15.5)$ & $131(12.3)$ & 0.126 \\
\hline Pinching & $81(5.8)$ & $7(2.1)$ & $74(6.9)$ & 0.001 \\
\hline Increasing at position change & $252(18.0)$ & $29(8.8)$ & $223(20.9)$ & $<0.001$ \\
\hline Breathing non-related & $1037(74.2)$ & $299(90.9)$ & $738(69.0)$ & $<0.001$ \\
\hline Radiating & $592(42.3)$ & $179(54.4)$ & $413(38.6)$ & $<0.001$ \\
\hline Additional symptoms & $937(67.1)$ & $249(75.7)$ & $688(64.4)$ & $<0.001$ \\
\hline
\end{tabular}

ACS Acute coronary syndrome, NRS Numeric rating scale, IQR Interquartile range

a'Typical chest pain is characterized by a retrosternal sensation of pressure or heaviness ("angina"), which may be intermittent (usually lasting several minutes) or persistent 
up is estimated to reach 20\% (undetermined diagnosis), we needed to include 1123 calls for non-traumatic chest pain for each sex. This sample size estimation concerns the training (derivation) dataset, which corresponds to two-thirds of the overall included patients. Thus, we needed to include a total of 1705 men and 1705 women for the derivation and validation datasets. Owing to an expected sex ratio of women/men of $40 \% / 60 \%$, we needed to include 4263 consecutive calls for non-traumatic chest pain.

\section{Analysis}

Data are expressed as numbers with percentages for categorial variables or means with standard deviation or medians with interquartile range [IQR] for continuous variables. Categorial data were compared by chi-square or Fisher exact test when appropriate and continuous data by Student $t$ or Mann and Whitney test as appropriate. Interexpert agreement for the final diagnosis was calculated with the Kappa coefficient and its 95\% confidence interval.

\section{Model development}

For each sex, we randomly selected a training (derivation) dataset from two-thirds of the data. Potential predictors were identified as variables associated with an ACS diagnosis significant at $p<0.2$ on bivariate analysis or already known to be associated in the literature. We used a backward stepwise logistic regression to retain the final independent predictive variables, based on both $p<0.05$ and the log-likelihood test. Then, we built a receiver operating characteristic (ROC) curve for each sex and defined the area under the ROC curve (AUC).

\section{Model validation}

The main characteristics of the derivation and validation models were compared for each sex by using appropriate bivariate statistical tests. The internal validity of the predictive model for each sex was tested in the validation dataset. First the discriminative performance of the score was evaluated with the validation dataset. Then, mean predictive probabilities were plotted against observed proportions of ACS in each quintile of predictive probabilities. Differences between observed and predicted probabilities were tested with the Hosmer-Lemeshow test.

All tests were two-sided, with statistical significance set at $p<0.05$. All analyses were performed with STATA v11.2 (StataCorpLP, College Station, TX, USA) and CART software (Salford System, CA 92126 USA).

\section{Results}

\section{Characteristics of study subjects}

Over the 18 months of the study, 4205 patients were enrolled. A final diagnosis was established for 3727 (89\%) (1630 [44\%] women and 2097 [56\%] men). Flowcharts of the final diagnosis by sex are presented in Fig. 1. Sensitivity analyses are presented in Appendix. Overall, 647 (17\%) participants had an ACS diagnosis (508 [24\%] men and 139 [9\%] women), including 260 (7\%) with STEMI. The interexpert agreement was excellent $($ Kappa $=0.91[0.89-0.93])$ for diagnosing ACS.

\section{Main results}

\section{Males with ACS}

The derivation dataset consisted of 1398 men. In total, 324 (23\%) men had an ACS diagnosis, 135/324 (42\%) with

Table 2 Final model for predicting ACS in males after multivariate analysis

\begin{tabular}{|c|c|c|c|c|}
\hline Variables & Regression coefficient & OR & $95 \% \mathrm{Cl}$ & $P$-value \\
\hline \multicolumn{5}{|l|}{ Age, y } \\
\hline$<40$ & 0 & 1 & & \\
\hline $40-50$ & 1.085 & 2.958 & {$[1.668-5.246]$} & $<0.001$ \\
\hline $50-60$ & 1.692 & 5.431 & {$[3.125-9.439]$} & $<0.001$ \\
\hline$\geq 60$ & 1.969 & 7.166 & {$[4.162-12.336]$} & $<0.001$ \\
\hline Tobacco use & 0.359 & 1.432 & {$[1.064-1.927]$} & 0.018 \\
\hline Severe pain (NRS $\geq 6$ ) & -1.016 & 0.362 & {$[0.143-0.917]$} & 0.032 \\
\hline Permanent pain & 0.385 & 1.469 & {$[1.09-1.981]$} & 0.012 \\
\hline Breathing non-related pain & 0.813 & 2.254 & {$[1.281-3.967]$} & 0.005 \\
\hline Retrosternal pain & 0.457 & 1.580 & {$[1.203-2.075]$} & 0.001 \\
\hline Radiating pain & 0.465 & 1.592 & [1.209-2.097] & 0.001 \\
\hline Additional symptoms & 0.066 & 1.068 & {$[0.735-1.551]$} & 0.729 \\
\hline Severe pain* Breathing non-related & 0.838 & 2.313 & {$[1.015-5.271]$} & 0.046 \\
\hline Severe pain*Additional symptoms & 0.850 & 2.339 & {$[1.202-4.553]$} & 0.012 \\
\hline
\end{tabular}

Because of missing values for one man, the analyses were performed on 1397 males OR Odds ratio, $\mathrm{Cl}$ Confidence interval, NRS Numeric rating scale

The symbol "*" indicate the interaction 
STEMI. The flowchart of the derivation dataset is in the Additional file 2. The general characteristics and type of pain for males are in Table 1. Men with an ACS diagnosis were older, more frequently had cardiovascular risk factors (except family history of coronary diseases and tobacco use) and had more typical pain typography characteristics than those without a diagnosis (Table 1).

Eight factors mostly contributed to the final model for predicting ACS in males: age, tobacco use, severe and permanent pain; retrosternal, breathing non-related and radiating pain; and additional symptoms (Table 2). The AUC value for the final male model was 0.76 (95\% CI $0.73-$ 0.79 ), with no differences between observed and predicted probabilities (Hosmer-Lemeshow test: $p=0.78$ ).

General characteristics were well balanced between the derivation dataset $(n=1398)$ and the validation dataset $(n=699)$. The accuracy of the male model to predict ACS was validated, with no differences between observed and predicted probabilities (Hosmer-Lemeshow test: $p=0.554$, Fig. 2a). The AUC value for the male prediction score was $0.76(0.73-0.80)$.

\section{Females with ACS}

The derivation dataset consisted of 1087 women. Overall, 92 (8\%) women had an ACS diagnosis, 32/92 (35\%) with STEMI. The flowchart of the derivation dataset is in the Additional file 2. The general characteristics and type of pain for females are in Table 3. Women with an ACS diagnosis were older, with more cardiovascular risk factors (except family history of coronary diseases and tobacco use) and had more typical pain typography than those without a diagnosis (Table 3).

Four factors mostly contributed to the final model for predicting ACS in females: age $\geq 60$ years,

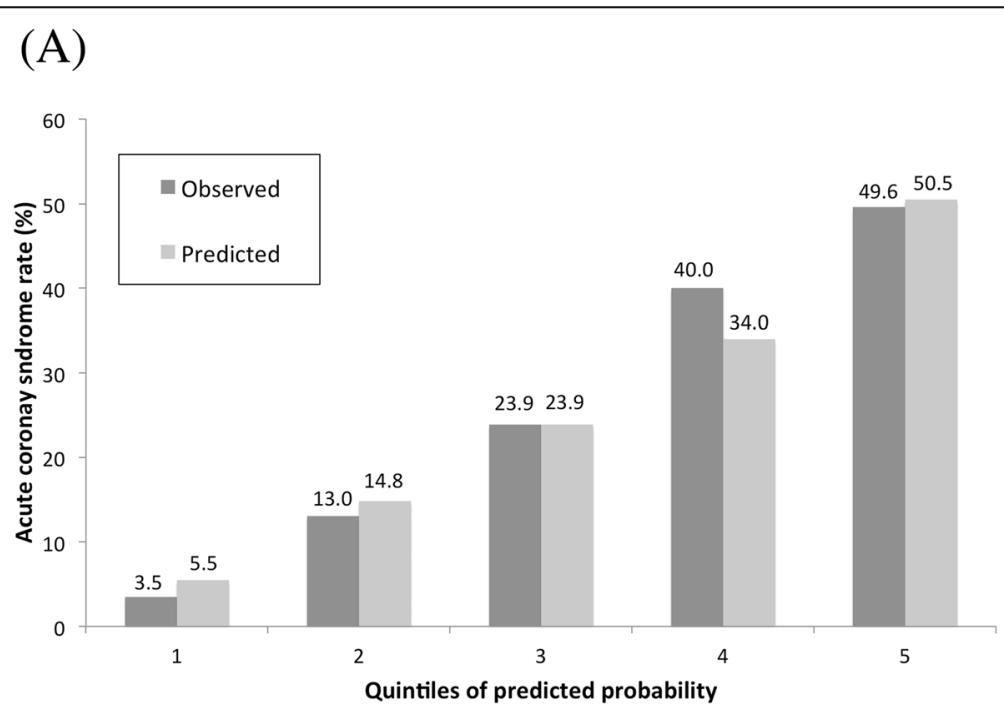

(B)

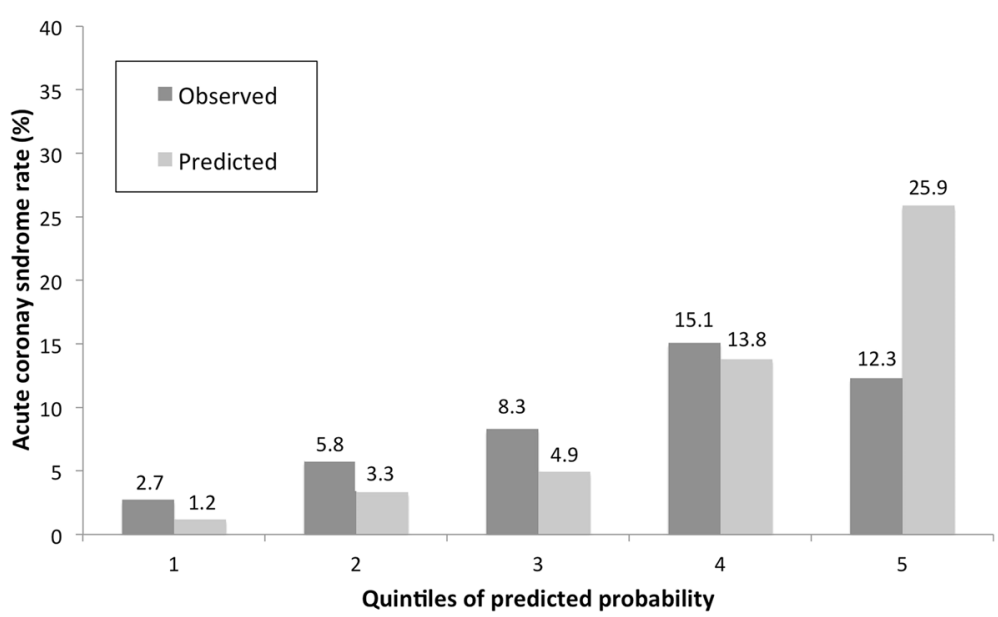

Fig. 2 Proportions of acute coronary syndrome cases observed and predicted for males (a) and females (b) 
Table 3 Characteristics and type of pain for female patients in the derivation set with and without a diagnosis of ACS

\begin{tabular}{|c|c|c|c|c|}
\hline & Total $(n=1087)$ & $\operatorname{ACS}(n=92)$ & No ACS $(n=995)$ & $p$ value \\
\hline Age, mean (SD), y, No. (\%) & $55.2(18.1)$ & $69.7(13.7)$ & $53.9(17.9)$ & $<0.001$ \\
\hline$<60$ & $215(19.8)$ & $9(9.8)$ & $206(20.7)$ & $<0.001$ \\
\hline$\geq 60$ & $445(40.9)$ & 75 (81.5) & $370(37.2)$ & \\
\hline \multicolumn{5}{|l|}{ Coexisting conditions, No. (\%) } \\
\hline Hypertension & $382(35.1)$ & $49(53.3)$ & $333(33.5)$ & $<0.001$ \\
\hline Personal coronary artery disease & $179(16.5)$ & $35(38.0)$ & $144(14.5)$ & $<0.001$ \\
\hline Family coronary artery disease & $178(16.4)$ & $10(10.9)$ & $168(16.9)$ & 0.136 \\
\hline Tobacco use & $249(22.9)$ & $12(13.0)$ & $237(23.8)$ & 0.019 \\
\hline Diabetes & $130(12.0)$ & $17(18.5)$ & $113(11.4)$ & 0.044 \\
\hline Dyslipidaemia & $207(19.0)$ & $28(30.4)$ & $179(18.0)$ & 0.004 \\
\hline \multicolumn{5}{|l|}{ Medication therapy, No. (\%) } \\
\hline Aspirin & $129(11.9)$ & $24(26.1)$ & $105(10.6)$ & $<0.001$ \\
\hline Clopidogrel & $64(5.9)$ & $16(17.4)$ & $48(4.8)$ & $<0.001$ \\
\hline Thyroid hormone & $90(8.3)$ & $7(7.6)$ & $83(8.3)$ & 0.807 \\
\hline Statin & $132(12.1)$ & $20(21.7)$ & $112(11.3)$ & 0.003 \\
\hline Severity of pain, median (IQR) & $5[4-7]$ & $5[4-7]$ & $5[4-7]$ & 0.496 \\
\hline \multicolumn{5}{|l|}{ Type of pain, No. (\%) } \\
\hline Severe pain (NRS $\geq 6$ ) & $489(45.0)$ & $42(45.7)$ & $447(45.0)$ & 0.900 \\
\hline Permanent & $272(25.0)$ & $24(26.1)$ & $248(24.9)$ & 0.805 \\
\hline Pain onset: & & & & 0.620 \\
\hline Crescendo & $207(19.1)$ & $14(15.2)$ & $193(19.4)$ & \\
\hline Abruptly & $483(44.4)$ & $43(46.7)$ & $440(44.2)$ & \\
\hline Unclassified & $397(36.5)$ & $35(38.1)$ & $362(36.4)$ & \\
\hline Circumstance of pain, No. (\%) & & & & 0.210 \\
\hline At rest & $914(84.1)$ & $75(81.5)$ & $839(84.3)$ & \\
\hline Sport or stress-related & $81(7.5)$ & $5(5.4)$ & $76(7.6)$ & \\
\hline Unclassified & $92(8.5)$ & $12(13.1)$ & $80(8.0)$ & \\
\hline \multicolumn{5}{|l|}{ Pain typography, No. (\%) } \\
\hline Typical chest pain ${ }^{a}$ & $616(56.7)$ & $64(69.6)$ & $552(55.5)$ & 0.009 \\
\hline Retrosternal & $461(42.4)$ & $52(56.5)$ & $409(41.1)$ & 0.004 \\
\hline Post-myocardial infarction angina & $41 / 179(22.9)$ & 9/35 (25.7) & $32 / 144(22.2)$ & 0.659 \\
\hline Peak type & $216(19.9)$ & $6(6.5)$ & $210(21.1)$ & 0.001 \\
\hline Burning & $132(12.1)$ & $14(15.2)$ & $118(11.9)$ & 0.345 \\
\hline Pinching & $53(4.9)$ & $1(1.1)$ & $52(5.2)$ & 0.122 \\
\hline Increasing at position change & $229(21.1)$ & $5(5.4)$ & $224(22.5)$ & $<0.001$ \\
\hline Breathing non-related & $769(70.7)$ & $83(90.2)$ & $686(68.9)$ & $<0.001$ \\
\hline Radiating & $475(43.7)$ & $52(56.5)$ & $423(42.5)$ & 0.010 \\
\hline Additional symptoms & 737 (67.9) & $70(76.1)$ & $667(67.1)$ & 0.077 \\
\hline
\end{tabular}

ACS Acute coronary syndrome, NRS Numeric rating scale, IQR Interquartile range

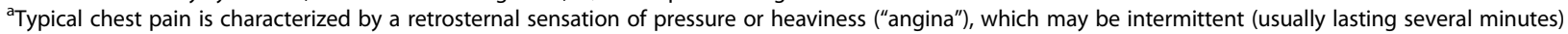
or persistent

personal history of coronary artery disease, and breathing non-related and radiating pain (Table 4). The AUC value for the final female model was 0.79 (95\% CI: 0.75-0.83), with no differences between observed and predicted probabilities (Hosmer-Lemeshow test: $p=0.70)$.

General characteristics were well balanced between the derivation dataset $(n=1087)$ and the validation 
dataset $(n=543)$. The female model's accuracy to predict ACS was not validated: predicted probabilities significantly differed from observed values (HosmerLemeshow test: $p=0.035$, Fig. $2 \mathrm{~b}$ ). The AUC value for the female prediction score was $0.67(0.60-0.74)$.

\section{Discussion}

\section{Main results}

For adults calling an EMCC with chest pain or discomfort, predictors of a final ACS diagnosis differed by sex. The discriminative performance of the model was poor for women and good for men.

\section{Explanation of the findings}

In our study, a predictive variable for ACS in males agreed with traditional typical angina. The pain characteristics were so typical that even the coexisting conditions, such previous coronary artery disease, did not significantly add to the prediction in the multivariate model. Therefore, decision-making in men is based on the characteristics of pain. For females, except for age and personal history of ACS, factors were not related to typical angina. Thus, decision-making in women is mainly based on criteria other than the pain characteristics. The initial presentation of ACS is well known to differ by sex. In contrast to men, women complain of discomfort or pain due to pinching or burning [16-20]. These discrepancies could be due to disparities in pathophysiology and aetiologies [26, 27]. Women with an ACS diagnosis were more likely to have a normal or mild angiographic coronary heart disease [19, 21]. Onetenth of ACS cases involve spontaneous coronary artery dissection, mainly in young women [28]. Myocardial infarction with a non-obstructive coronary artery (MINOCA) occurs mostly in women and includes coronary endothelial dysfunction, myocarditis or Takostubo syndrome [1]. In these pathologies, traditional cardiovascular risk factors have a low implication.

The identification of a woman presenting an ACS remains a challenge. The mortality rate is higher in women than men because of their atypical initial presentation, older age, and less recourse to coronary angiography [21, 29, 30]. When adjusted on the same level of care, mortality is similar between the sexes, which led the authors of one study to advocate for a diagnosis of ACS in women [31, 32]. In our study, the discriminative performance of our model to predict ACS in women was not reproducible. Determinants were limited in number, not typical and above all not reproducible. An explanation is a potential lack of knowledge regarding variables to investigate to detect ACS in women. Currently, women are assessed with the variables used for men. Specific factors in women need to be investigated.

\section{Strengths}

Our study is the first prospective multicentric study to focus on predicting an ACS diagnosis in patients calling an EMCC for chest pain or discomfort. Other studies analysed patients with an established ACS diagnosis and cared for in an emergency department or cardiology department. Furthermore, this large study improves on the small number of studies evaluating the effectiveness of EMCC [33].

\section{Limitations}

We excluded uncommunicative patients because they could experience impending death, an at-risk sign. This state has already been highlighted in the evaluation of imminent delivery at an EMCC [34]. Thus, we investigated ACS as the only outcome without considering other life threatening causes of chest pain. The outcome was established retrospectively by experts, witch could be consider as subjective and potentially biased. Nevertheless, decision was based on medical records that were collected prospectively, limiting this bias. Lastly, in women we failed to propose a model that accurately predicted an ACS diagnosis in the validation sample.

\section{Conclusions}

A sex disparity exists in screening for ACS in people calling an EMCC because of chest pain. A score could be proposed for men. For women, a better understanding of pathophysiology and symptomatology are needed to increase the detection of ACS.

Table 4 Final model for predicting ACS in males after multivariate analysis

\begin{tabular}{lllll}
\hline Variables & Regression coefficient & OR & $95 \% \mathrm{Cl}$ & $P$ value \\
\hline Age $\geq 60$ y & 1.716 & 5.564 & {$[3.160-9.800]$} & $<0.001$ \\
Personal history of coronary artery disease & 0.603 & 1.828 & {$[1.120-2.982]$} & 0.016 \\
Breathing non-related pain & 1.017 & 2.765 & {$[1.346-5.678]$} & 0.006 \\
Radiating pain & 0.469 & 1.598 & {$[1.017-2.513]$} & 0.042 \\
\hline
\end{tabular}

Because of missing values for one woman, the analyses were performed on 1086 females OR Odds ratio, $\mathrm{Cl}$ Confidence interval 


\section{Appendix}

Table $\mathbf{5}$ Characteristics and type of pain by availability of diagnosis

\begin{tabular}{|c|c|c|c|}
\hline & Diagnosis unknown $(n=478)$ & Diagnosis established $(n=3727)$ & $P$ value \\
\hline Female, No. (\%) & $212(44.4)$ & $1630(43.7)$ & 0.789 \\
\hline Age, mean (SD), y, No. (\%) & $48.1(16.5)$ & $55.9(17.0)$ & $<0.001$ \\
\hline$<40$ & $147(30.8)$ & $764(20.5)$ & $<0.001$ \\
\hline $40-50$ & $133(27.8)$ & $804(21.6)$ & \\
\hline $50-60$ & 95 (19.9) & $790(21.2)$ & \\
\hline$\geq 60$ & $103(21.5)$ & $1369(36.7)$ & \\
\hline \multicolumn{4}{|l|}{ Coexisting conditions, No. (\%) } \\
\hline Hypertension & $84(17.6)$ & $1181(31.7)$ & $<0.001$ \\
\hline Personal coronary artery disease & $71(14.9)$ & $857(23.0)$ & $<0.001$ \\
\hline Family coronary artery disease & $82(17.2)$ & $603(16.2)$ & 0.587 \\
\hline Tobacco use & $220(46.0)$ & $1244(33.4)$ & $<0.001$ \\
\hline Diabetes & $20(4.2)$ & $462(12.4)$ & $<0.001$ \\
\hline Dyslipidaemia & $77(16.1)$ & $838(22.5)$ & 0.001 \\
\hline \multicolumn{4}{|l|}{ Medication therapy, №. (\%) } \\
\hline Aspirin & $55(11.5)$ & $624(16.7)$ & 0.003 \\
\hline Clopidogrel & $31(6.5)$ & $410(11.0)$ & 0.002 \\
\hline Thyroid hormone & $20(4.2)$ & $152(4.1)$ & 0.912 \\
\hline Statin & $40(8.4)$ & $589(15.8)$ & $<0.001$ \\
\hline Severity of pain, median (IQR) & $5[3-6]$ & $5[3-7]$ & 0.032 \\
\hline \multicolumn{4}{|l|}{ Type of pain, No. (\%) } \\
\hline Severe pain (NRS $\geq 6$ ) & $177(37.1)$ & $1616(43.4)$ & 0.009 \\
\hline Permanent & $112(23.4)$ & $947(25.4)$ & 0.348 \\
\hline Pain onset: & & & 0.057 \\
\hline Crescendo & $113(23.6)$ & $782(21.0)$ & \\
\hline Abruptly & $179(37.4)$ & $1608(43.1)$ & \\
\hline Unclassified & $186(38.9)$ & $1337(35.9)$ & \\
\hline Circumstance of call, No. (\%) & & & 0.733 \\
\hline At rest & $382(79.9)$ & $3026(81.2)$ & \\
\hline Sport or stress related & $52(10.9)$ & $395(10.6)$ & \\
\hline Unclassified & $44(9.2)$ & $306(8.2)$ & \\
\hline \multicolumn{4}{|l|}{ Pain typography, No. (\%) } \\
\hline Typical chest pain ${ }^{a}$ & $231(48.3)$ & $2121(56.9)$ & $<0.001$ \\
\hline Retrosternal & $170(35.6)$ & $1721(46.2)$ & \\
\hline Post-myocardial infarction angina & $14 / 71(19.7)$ & 241/857 (28.1) & 0.127 \\
\hline Peak type & $143(29.9)$ & $701(18.8)$ & $<0.001$ \\
\hline Burning & $59(12.3)$ & $478(12.8)$ & 0.766 \\
\hline Pinching & $19(4.0)$ & $204(5.5)$ & 0.169 \\
\hline Increasing at position change & $119(24.9)$ & $726(19.5)$ & 0.005 \\
\hline Breathing non-related & $311(65.1)$ & $273873.5)$ & $<0.001$ \\
\hline Radiating & $198(41.4)$ & $1637(43.9)$ & 0.299 \\
\hline Additional symptoms & $302(63.3)$ & $2521(67.7)$ & 0.056 \\
\hline
\end{tabular}

NRS Numeric rating scale

${ }^{\text {a } T y p i c a l ~ c h e s t ~ p a i n ~ i s ~ c h a r a c t e r i z e d ~ b y ~ a ~ r e t r o s t e r n a l ~ s e n s a t i o n ~ o f ~ p r e s s u r e ~ o r ~ h e a v i n e s s ~(' a n g i n a '), ~ w h i c h ~ m a y ~ b e ~ i n t e r m i t t e n t ~(u s u a l l y ~ l a s t i n g ~ s e v e r a l ~ m i n u t e s) ~}$ or persistent 


\section{Supplementary information}

Supplementary information accompanies this paper at https://doi.org/10. 1186/s13049-019-0670-y.

Additional file 1. Standardized form for gathering data on patient characteristics, cardiovascular risk factors, medical history and clinical presentation

Additional file 2. Flowchart in the derivation set by sex.

\section{Abbreviations}

ACS: Acute Coronary Syndrome; AUC: Area Under the ROC Curve;

ECG: Electrocardiography; EMCC: Emergency Medical Communication Centre; IQR: Interquartile Range; MICU: Mobile Intensive Care Unit;

MINOCA: Myocardial infarction with a non-obstructive coronary artery; ROC: Receiver Operating Characteristic; STEMI: ST Elevation Myocardial Infarction

\section{Acknowledgments}

The authors thank Mrs. Vanessa Houze-Cerfon for her help in monitoring participants.

\section{Transparency declaration}

The lead authors (the manuscript's guarantors) affirm that the manuscript is an honest, accurate, and transparent account of the study being reported; that no important aspects of the study have been omitted; and that any discrepancies from the study as planned (and, if relevant, registered) have been explained.

\section{Authors' contributions}

Conception and design: SHYK, VB, JLD and SC; acquisition of data: CP, AB, ET, XC and SC; analysis: SHYK and VB; interpretation of data: PGR, SHYK, VB and SC; drafting the article: PGR and SC; critical revision for important intellectual content: all authors; final approval of the version to be published: all authors.

\section{Funding}

The study was supported by the Programme Hospitalier de Recherche Clinique 2009 of the French Ministry of Health. The funders of the study had no role in study design, data collection, data analysis, data interpretation, or writing of the report.

\section{Availability of data and materials}

The statistical code and technical processes are available from the time of publication. Appropriate institutional agreements will be required for anonymised participant data transfer. Requests should be made via email to the corresponding author along with an analysis proposal.

\section{Ethics approva}

In accordance with French law, our local ethics committee considered that patient oral consent could be sufficient for participation in this observational study. Data collection and storage were approved by the "Comité consultative sur le traitement de l'information en matière de recherché" (CCTIRS) and the "Commission nationale informatique et liberté" (CNIL). This study is registered with ClinicalTrials.gov, number NCT02042209.

\section{Competing interests}

All authors have completed the Unified Competing Interest form (available on request from the corresponding author) and declare: no support from any organisation for the submitted work; no financial relationships with any organisations that might have an interest in the submitted work in the previous 3 years, no other relationships or activities that could appear to have influenced the submitted work.

\section{Author details}

'Emergency Department, Toulouse University Hospital, 31000 Toulouse, France. ${ }^{2}$ UMR 1027, Paul Sabatier University Toulouse III, Inserm, Toulouse, France. ${ }^{3}$ SAMU 92, Assistance Publique-Hôpitaux de Paris, Hôpital Raymond Poincaré, 92380 Garches, France. ${ }^{4}$ SAMU 33, CHU de Bordeaux, 33076 Bordeaux cedex, France. ${ }^{5}$ Unité de Soutien Méthodologique à la Recherche (USMR), Centre Hospitalier Universitaire de Toulouse (CHU de Toulouse), Toulouse, France. 'Department of Cardiology, Rangueil University Hospital,
Toulouse, France. ${ }^{7}$ Department of Emergency, CHU de la Réunion, allée des Topazes, Université de la Réunion, 97400 Saint Denis, France.

Received: 4 July 2019 Accepted: 16 September 2019 Published online: 17 October 2019

\section{References}

1. Ibanez B, James S, Agewall S, Antunes MJ, Bucciarelli-Ducci C, Bueno H, et al. 2017 ESC guidelines for the management of acute myocardial infarction in patients presenting with ST-segment elevationThe task force for the management of acute myocardial infarction in patients presenting with ST-segment elevation of the European Society of Cardiology (ESC). Eur Heart J. 2018;39(2):119-77.

2. Mehta LS, Beckie TM, DeVon HA, Grines CL, Krumholz HM, Johnson MN, et al. Acute myocardial infarction in women: a scientific statement from the American Heart Association. Circulation. 2016;133(9):916-47.

3. Møller TP, Ersbø\|ll AK, Tolstrup JS, Østergaard D, Viereck S, Overton J, et al. Why and when citizens call for emergency help: an observational study of 211,193 medical emergency calls. Scand J Trauma Resusc Emerg Med. 2015; 23:88.

4. Rawshani A, Larsson A, Gelang C, Lindqvist J, Gellerstedt M, Bång A, et al. Characteristics and outcome among patients who dial for the EMS due to chest pain. Int J Cardiol. 2014;176(3):859-65.

5. Gellerstedt M, Rawshani N, Herlitz J, Bång A, Gelang C, Andersson J-O, et al. Could prioritisation by emergency medicine dispatchers be improved by using computer-based decision support? A cohort of patients with chest pain. Int J Cardiol. 2016;220:734-8.

6. Charpentier S, Beaune S, Joly LM, Khoury A, Duchateau F-X, Briot R, et al. Management of chest pain in the French emergency healthcare system: the prospective observational EPIDOULTHO study. 2018;25(6):404-10.

7. Newman JD, Davidson KW, Ye S, Shaffer JA, Shimbo D, Muntner P. Gender differences in calls to 9-1-1 during an acute coronary syndrome. Am J Cardiol. 2013;111(1):58-62.

8. Leurent G, Garlantézec R, Auffret V, Hacot JP, Coudert I, Filippi E, et al. Gender differences in presentation, management and inhospital outcome in patients with ST-segment elevation myocardial infarction: data from 5000 patients included in the ORBI prospective French regional registry. Arch Cardiovasc Dis. 2014;107(5):291-8

9. Melberg T, Kindervaag B, Rosland J. Gender-specific ambulance priority and delays to primary percutaneous coronary intervention: a consequence of the patients' presentation or the management at the emergency medical communications center? Am Heart J. 2013;166(5):839-45.

10. Manzo-Silberman S, Assez N, Vivien B, Tazarourte K, Mokni T, Bounes V, et al. Management of non-traumatic chest pain by the French emergency medical system: insights from the DOLORES registry. Arch Cardiovasc Dis. 2015:108(3):181-8.

11. Rawshani N, Rawshani A, Gelang C, Herlitz J, Bång A, Andersson J-O, et al. Could ten questions asked by the dispatch center predict the outcome for patients with chest discomfort? Int J Cardiol. 2016;209:223-5.

12. Rawshani A, Rawshani N, Gelang C, Andersson J-O, Larsson A, Bång A, et al. Emergency medical dispatch priority in chest pain patients due to life threatening conditions: a cohort study examining circadian variations and impact of the education. Int J Cardiol. 2017;236:43-8.

13. Kontos MC, Jesse RL. Evaluation of the emergency department chest pain patient. Am J Cardiol. 2000;85(5A):32B-9B.

14. Goldberg R, Goff D, Cooper L, Luepker R, Zapka J, Bittner V, et al. Age and sex differences in presentation of symptoms among patients with acute coronary disease: the REACT trial. Rapid early action for coronary treatment. Coron Artery Dis. 2000;11(5):399-407.

15. Howard BV, Rodriguez BL, Bennett PH, Harris MI, Hamman R, Kuller LH, et al. Prevention conference VI: diabetes and cardiovascular disease: writing group I: epidemiology. Circulation. 2002;105(18):e132-7.

16. Canto JG, Goldberg RJ, Hand MM, Bonow RO, Sopko G, Pepine CJ, et al. Symptom presentation of women with acute coronary syndromes: myth vs reality. Arch Intern Med. 2007:167(22):2405-13.

17. Khan NA, Daskalopoulou SS, Karp I, Eisenberg MJ, Pelletier R, Tsadok MA, et al. Sex differences in acute coronary syndrome symptom presentation in young patients. JAMA Intern Med. 2013;173(20):1863-71.

18. D'Onofrio G, Safdar B, Lichtman JH, Strait KM, Dreyer RP, Geda M, et al. Sex differences in reperfusion in young patients with ST-segment-elevation 
myocardial infarction: results from the VIRGO study. Circulation. 2015; 131(15):1324-32.

19. Dey S, Flather MD, Devlin G, Brieger D, Gurfinkel EP, Steg PG, et al. Sexrelated differences in the presentation, treatment and outcomes among patients with acute coronary syndromes: the global registry of acute coronary events. Heart. 2009;95(1):20-6.

20. Arora G, Bittner V. Chest pain characteristics and gender in the early diagnosis of acute myocardial infarction. Curr Cardiol Rep. 2015;17(2):5.

21. Berger JS, Elliott L, Gallup D, Roe M, Granger CB, Armstrong PW, et al. Sex differences in mortality following acute coronary syndromes. JAMA. 2009; 302(8):874-82.

22. Velders MA, Boden $H$, van Boven AJ, van der Hoeven BL, Heestermans AACM, Cannegieter SC, et al. Influence of gender on ischemic times and outcomes after ST-elevation myocardial infarction. Am J Cardiol. 2013;111(3): 312-8.

23. Thygesen K, Alpert JS, Jaffe AS, Simoons ML, Chaitman BR, White HD, et al. Third universal definition of myocardial infarction. Eur Heart J. 2012;33(20): 2551-67.

24. Concato J, Feinstein AR, Holford TR. The risk of determining risk with multivariable models. Ann Intern Med. 1993;118(3):201-10.

25. Harrell FE, Lee KL, Matchar DB, Reichert TA. Regression models for prognostic prediction: advantages, problems, and suggested solutions. Cancer Treat Rep. 1985;69(10):1071-7.

26. Shaw LJ, Bugiardini R, Merz CNB. Women and ischemic heart disease: evolving knowledge. J Am Coll Cardiol. 2009;54(17):1561-75.

27. Aggarwal NR, Patel HN, Mehta LS, Sanghani RM, Lundberg GP, Lewis SJ, et al. Sex differences in ischemic heart disease: advances, obstacles, and next steps. Circ Cardiovasc Qual Outcomes. 2018;11(2):e004437.

28. Adlam D, Alfonso F, Maas A, Vrints C. Writing committee. European Society of Cardiology, acute cardiovascular care association, SCAD study group: a position paper on spontaneous coronary artery dissection. Eur Heart J. 2018. 39(36):3353-68.

29. Pancholy SB, Shantha GPS, Patel T, Cheskin LJ. Sex differences in short-term and long-term all-cause mortality among patients with ST-segment elevation myocardial infarction treated by primary percutaneous intervention: a meta-analysis. JAMA Intern Med. 2014;174(11):1822-30.

30. Milcent C, Dormont B, Durand-Zaleski I, Steg PG. Gender differences in hospital mortality and use of percutaneous coronary intervention in acute myocardial infarction: microsimulation analysis of the 1999 nationwide French hospitals database. Circulation. 2007;115(7):833-9.

31. Mehilli J, Kastrati A, Dirschinger J, Pache J, Seyfarth M, Blasini R, et al. Sexbased analysis of outcome in patients with acute myocardial infarction treated predominantly with percutaneous coronary intervention. JAMA. 2002;287(2):210-5.

32. Schiele F, Meneveau N, Seronde M-F, Descotes-Genon V, Chopard R, Janin $\mathrm{S}$, et al. Propensity score-matched analysis of effects of clinical characteristics and treatment on gender difference in outcomes after acute myocardial infarction. Am J Cardiol. 2011;108(6):789-98.

33. Bohm K, Kurland L. The accuracy of medical dispatch - a systematic review. Scand J Trauma Resusc Emerg Med. 2018;26(1):94.

34. Berthier F, Branger B, Lapostolle F, Morel P, Guilleux AM, Debierre V, et al. Score predicting imminent delivery in pregnant women calling the emergency medical service. Eur J Emerg Med. 2009;16(1):14-22.

\section{Publisher's Note}

Springer Nature remains neutral with regard to jurisdictional claims in published maps and institutional affiliations.

Ready to submit your research? Choose BMC and benefit from:

- fast, convenient online submission

- thorough peer review by experienced researchers in your field

- rapid publication on acceptance

- support for research data, including large and complex data types

- gold Open Access which fosters wider collaboration and increased citations

- maximum visibility for your research: over $100 \mathrm{M}$ website views per year

At BMC, research is always in progress.

Learn more biomedcentral.com/submissions 